\title{
ASO Author Reflections: Sentinel Lymph Node Biopsy Trend in Melanoma: The More the Merrier
}

\author{
Mary-Ann El Sharouni, $\mathrm{MD}^{1}$, Arjen Witkamp, $\mathrm{MD}, \mathrm{PhD}^{2}$, Vigfús Sigurdsson, $\mathrm{MD}, \mathrm{PhD}^{\mathbf{1}}$, and \\ Paul J. van Diest, $\mathrm{MD}, \mathbf{P h D}^{3}$ \\ ${ }^{1}$ Department of Dermatology, University Medical Centre Utrecht, Utrecht University, Utrecht, The Netherlands; \\ ${ }^{2}$ Department of Surgery, University Medical Centre Utrecht, Utrecht University, Utrecht, The Netherlands; ${ }^{3}$ Department of \\ Pathology, University Medical Centre Utrecht, Utrecht University, Utrecht, The Netherlands
}

\section{PAST}

In recent years, recommendations in guidelines for cutaneous melanoma have changed considerably. Although guideline recommendations for its indication differ slightly per country, it is believed that sentinel lymph node biopsy (SLNB) should be considered for patients with more than $1 \mathrm{~mm}$ Breslow thickness. ${ }^{1-3}$ Until recently, SLNB was performed for extra prognostic information to inform patients as optimally as possible about their prognosis. This study aimed to evaluate the trend in SLNB enactment during a 15-year period in The Netherlands.

\section{PRESENT}

Only 9761 (39.7\%) of all eligible patients underwent SLNB. Although the trend showed an increase in SLNB enactment, from $39.1 \%$ in 2003 , still only $47.8 \%$ of all eligible patients in 2014 underwent SLNB. Variables significantly associated with non-enactment were female gender, older age, and melanoma located on the head and neck. $^{4}$

ASO Author Reflections offer a brief invited commentary on the article, Trends in Sentinel Lymph Node Biopsy Enactment for Cutaneous Melanoma. Ann Surg Oncol. 2019;26:1494-502.

(C) The Author(s) 2019

First Received: 10 July 2019; Published Online: 5 September 2019

M.-A. El Sharouni, MD

e-mail: m.a.elsharouni-2@umcutrecht.nl

\section{FUTURE}

A positive SLNB has become the gateway to adjuvant immunotherapy for melanoma patients rather than to lymph node dissection. ${ }^{5}$ Because this is a major change in the reason for performing an SLNB, the authors believe their data underscore the fact that many eligible patients still are denied an SLNB, and much work remains to be done to ensure that this procedure will be performed when indicated. The authors hope their report contributes to more awareness with regard to SLNB and eventually to a better prognosis for melanoma patients.

DISCLOSURES There are no conflicts of interest.

OPEN ACCESS This article is distributed under the terms of the Creative Commons Attribution 4.0 International License (http://crea tivecommons.org/licenses/by/4.0/), which permits unrestricted use, distribution, and reproduction in any medium, provided you give appropriate credit to the original author(s) and the source, provide a link to the Creative Commons license, and indicate if changes were made.

\section{REFERENCES}

1. Balch CM, Gershenwald JE, Soong SJ, et al. Final version of 2009 AJCC melanoma staging and classification. J Clin Oncol. 2009;27:6199-206.

2. Bichakjian CK, Halpern AC, Johnson TM, et al. Guidelines of care for the management of primary cutaneous melanoma. American Academy of Dermatology. $J$ Am Acad Dermatol. 2011;65:1032-47.

3. Chakera AH, Hesse B, Burak Z et al. EANM-EORTC general recommendations for sentinel node diagnostics in melanoma. Eur J Nucl Med Mol Imaging. 2009;36:1713-42. 
4. El Sharouni MA, Witkamp AJ, Sigurdsson V, et al. Trends in sentinel lymph node biopsy enactment for cutaneous melanoma. Ann Surg Oncol. 2019;26:1494-502.

5. Eggermont AM, Robert C, Ribas A. The new era of adjuvant therapies for melanoma. Nat Rev Clin Oncol. 2018;15:535-6.
Publisher's Note Springer Nature remains neutral with regard to jurisdictional claims in published maps and institutional affiliations. 